\section{One evidence base; three stories: do opioids relieve chronic breathlessness?}

\section{ABSTRACT}

The efficacy of low-dose systemic opioids for chronic breathlessness was questioned by the recent Cochrane review by Barnes et al. We examined the reasons for this conflicting finding and re-evaluated the efficacy of systemic opioids. Compared with previous meta-analyses, Barnes et al reported a smaller effect and lower precision, but did not account for matched data of crossover trials (11/12 included trials) and added a risk-of-bias criterion (sample size). When re-analysed to account for crossover data, opioids decreased breathlessness (standardised mean differences $-0.32 ;-0.18$ to $-0.47 ; \mathrm{I}^{2}=44.8 \%$ ) representing a clinically meaningful reduction of 0.8 points $(0-10$ numerical rating scale), consistent across meta-analyses.

\section{INTRODUCTION}

Chronic breathlessness ${ }^{1}$ is common across a range of advanced diseases and associated with major adverse health outcomes. ${ }^{2}$ The candidate treatment with best evidence to date is regular, low-dose, non-nebulised (systemic) morphine. ${ }^{2}$ The efficacy of low-dose systemic opioids was supported by a Cochrane review by Jennings et $a l,,^{34}$ an adequately powered crossover trial in 2003,5 and the meta-analysis in people with severe COPD by Ekström et al. ${ }^{6}$

A new Cochrane meta-analysis by Barnes et al, ${ }^{7}$ drawing from a similar evidence base, reported a smaller benefit of opioids than the other reviews, and wider 95\% CIs which nearly crossed zero. The risk of bias was rated as 'high' for all studies; previous ratings were mainly 'unclear' or 'low'. ${ }^{4} 6$ Barnes et al rated the quality of evidence for opioids for breathlessness as 'very low'.

We aimed to determine the reasons for the different conclusions and to

Table 1 Characteristics of meta-analyses of systemic opioids for breathlessness

\begin{tabular}{|c|c|c|c|}
\hline $\begin{array}{l}\text { Characteristic of } \\
\text { meta-analysis }\end{array}$ & Jennings et $a l^{3}$ & Ekström et al ${ }^{6}$ & Barnes et $\mathrm{al}^{7}$ \\
\hline $\begin{array}{l}\text { Design of included } \\
\text { studies }(n)\end{array}$ & Double-blind RCTs & Double-blind RCTs & Double-blind RCTs \\
\hline $\mathrm{N}$ studies & 9 (all crossover trials) & 8 (all crossover trials) & 12 (1 parallel and 11 crossover trials) \\
\hline $\mathrm{N}$ trial participants & 102 & 118 & 198 \\
\hline $\begin{array}{l}\text { Population (n trial } \\
\text { participants) }\end{array}$ & $\begin{array}{l}\text { COPD }(n=80) \text { Chronic heart } \\
\text { failure }(n=12) \text { Cancer }(n=10)\end{array}$ & COPD $(n=113)$ Other $(n=5)$ & COPD $(n=107)$ CHF $(n=47)$ Cancer $(n=41)$ Other $(n=3)$ \\
\hline Intervention & Oral or parenteral opioid & Oral or parenteral opioid & Oral or parenteral opioid \\
\hline Comparison & Placebo & Placebo & $\begin{array}{l}\text { Placebo or any other pharmacological or non-pharmacological } \\
\text { interventions that were directly compared with the opioid treatment } \\
\text { (only two trials used non-placebo comparator) }\end{array}$ \\
\hline $\begin{array}{l}\text { Duration of treatment ( } \mathrm{n} \\
\text { studies) }\end{array}$ & $\begin{array}{l}\text { Single or few doses }(\mathrm{N}=5) \text {; } \\
\text { longer treatment of } 1-6 \text { weeks } \\
(n=4)\end{array}$ & $\begin{array}{l}\text { Single dose or } 1 \text { day }(n=3) \text {; } \\
4 \text { days to } 6 \text { weeks }(n=5)\end{array}$ & Single dose or $1-2$ days $(n=7) ; 4$ days to 6 weeks $(n=5)$ \\
\hline $\begin{array}{l}\text { Statistical method for } \\
\text { pooling }\end{array}$ & $\begin{array}{l}\text { Random effects model. } \\
\text { Change on different scales } \\
\text { compared as SMDs }\end{array}$ & $\begin{array}{l}\text { Random effects model. } \\
\text { Change on different scales } \\
\text { compared as SMDs }\end{array}$ & $\begin{array}{l}\text { Fixed effect models. } \\
\text { Changes compared as MD when on the same scale and SMD when on } \\
\text { separate scales, and separately for change from baseline and postscores. } \\
\text { Random effects model was used in a sensitivity analysis }\end{array}$ \\
\hline $\begin{array}{l}\text { Accounted for crossover } \\
\text { designs }\end{array}$ & Yes & Yes & No (analysed data as from parallel trials) \\
\hline \multicolumn{4}{|c|}{ Findings for whole study population } \\
\hline $\begin{array}{l}\text { Pooled effect of opioids } \\
\left(95 \% \mathrm{Cl} ; \mathrm{I}^{2} ; \mathrm{n} \text { trial }\right. \\
\text { participants)* }\end{array}$ & $\begin{array}{l}\text { SMD }-0.40(-0.63 \text { to }-0.17 \\
\left.\mathrm{I}^{2}=42.3 \% ; n=102\right)\end{array}$ & $\begin{array}{l}\text { SMD }-0.34(-0.58 \text { to }-0.10 ; \\
\left.\mathrm{I}^{2}=0 \% ; n=118\right)\end{array}$ & $\begin{array}{l}\text { Oral opioid, change from baseline: SMD } 0.07\left(-0.30 \text { to } 0.44 ; I^{2}=65 \% \text {; }\right. \\
n=116) \\
\left.\text { Oral opioid, postscores: SMD }-0.27 \text { ( }-0.56 \text { to } 0.02 ; I^{2}=0 \% ; n=190\right) \\
\text { Subcutaneous opioid, change from baseline: MD } 0.20(-2.50 \text { to } 2.90 \text {; } \\
n=20)\end{array}$ \\
\hline $\begin{array}{l}\text { Stated quality of } \\
\text { evidence }\end{array}$ & Not stated & Moderate (GRADE) & $\begin{array}{l}\text { Not stated for systemic opioids } \\
\text { For opioids overall: very low for change from baseline and low for } \\
\text { postscores (GRADE) } †\end{array}$ \\
\hline \multicolumn{4}{|c|}{ Findings in COPD participants } \\
\hline $\begin{array}{l}\text { Pooled effect of opioids } \\
\left(95 \% \mathrm{Cl} ; \mathrm{I}^{2} ; n \text { trial }\right. \\
\text { participants)* }\end{array}$ & $\begin{array}{l}\text { SMD }-0.26(-0.44 \text { to } 0.08 ; \\
\left.I^{2}=23.6 \% ; n=80\right) \dagger\end{array}$ & $\begin{array}{l}\text { SMD }-0.34(-0.58 \text { to }-0.10 \\
\left.\mathrm{I}^{2}=0 \% ; n=118\right)\end{array}$ & $\begin{array}{l}\text { Change from baseline: SMD }-0.49\left(-1.08 \text { to } 0.10 ; I^{2}=0 \% ; n=46\right) \dagger \\
\text { Postscores: SMD }-0.21\left(-0.45 \text { to } 0.04 ; I^{2}=0 \% ; n=262\right) \dagger\end{array}$ \\
\hline $\begin{array}{l}\text { Stated quality of } \\
\text { evidence (criteria) }\end{array}$ & Not stated & Moderate (GRADE) & Not stated \\
\hline Risk of bias assessment & $\begin{array}{l}\text { Using Jadad score of methods } \\
\text { of randomisation and blinded. } \\
\text { Most items were rated as } \\
\text { unclear }\end{array}$ & $\begin{array}{l}\text { Using the Cochrane risk of bias } \\
\text { tool. Ratings were low or unclear } \\
\text { for all items; no item was rated } \\
\text { as high }\end{array}$ & $\begin{array}{l}\text { Using the Cochrane risk of bias tool as well as an additional item based } \\
\text { on study size: } \geq 200 \text { (low risk), } 50-199 \text { (unclear risk) and }<50 \text { (high risk) } \\
\text { participants in each treatment arm. } \\
\text { All items in the Cochrane risk of bias tool were rated as low or unclear } \\
\text { except three items rated as high: performance bias }(n=1) \text {, detection bias } \\
\text { ( } n=1) \text { and other bias ( } n=1) . \dagger \\
\text { Risk of study size bias was rated as high risk for all studies }\end{array}$ \\
\hline
\end{tabular}

Characteristics are for trials included in each published meta-analysis. ${ }^{367}$

* Negative estimate indicates reduction in breathlessness by opioids compared with placebo.

tIncluded both trials of systemic and nebulised opioids which were not reported separately.

CHF, congestive heart failure; GRADE, Grading of Recommendations Assessment, Development, and Evaluation; $I^{2}$, proportion of the total variance in effect estimates that are between studies; MD, mean difference; RCT, randomised controlled trial; SMD, standardised mean difference. 
re-evaluate the efficacy of systemic opioids for chronic breathlessness.

\section{METHODS}

Data were extracted from the published meta-analyses by Jennings et $a l,^{3}{ }^{4}$ Ekström et $a l^{6}$ and Barnes et $a l^{7}$ (by ME), and cross-validated (DCC and MJJ) regarding study populations, designs, interventions and methods, for the whole study population and in participants with COPD, respectively.

Breathlessness measures were analysed as standardised mean differences (SMD). ${ }^{8}$ For crossover trials, the SE was estimated using the crossover information, directly from the published report or calculated from significance test statistics as recommended. ${ }^{8}$ The effect of opioids compared with placebo was analysed using a random effects model. A detailed description of the statistical methods is given in the online supplementary file (appendix 1).

\section{RESULTS}

\section{Included studies}

All included studies were double-blind, placebo-controlled randomised trials; 13/14 studies were crossover designs (table 1). Jennings et al and Barnes et al included patients with any advanced, lifelimiting disease, whereas Ekström et al restricted the analysis to patients with COPD. Research questions, interventions, comparisons and treatment durations were similar between the three meta-analyses (table 1).

The study populations overlapped significantly with over half of the studies by Barnes et al also included in studies by Jennings et al and Ekström et al (see online supplementary table S1). For two studies omitted by Barnes et al, the reasons for exclusion were not stated.

\section{Efficacy}

In contrast to the other meta-analyses, Barnes et al used a fixed effects model which does not account for variations in the true effect between studies, and analysed all data as if from parallel trials and did not account for matched crossover data $(11 / 12 ; 92 \%$ of included studies).

Opioids were associated with a decrease in breathlessness in both studies by Jennings et al and Ekström et al (table 1). In the primary analysis of Ekström et al, systemic opioids improved breathlessness in COPD outpatients measured at steady state (5 studies, 91 participants), SMD -0.33 (95\% CI -0.52 to -0.14 ).

Barnes et al split the analysis by route of administration and type of outcome measure (table 1). Point estimates of efficacy ranged from SMD -0.27 (oral opioid, post-treatment scores) to mean difference 0.20 (subcutaneous opioid, change scores). Precision was markedly lower across all analyses. The estimate for COPD in the study by Barnes et al included all types of both systemic and nebulised opioids. Estimates for systemic opioids or efficacy at steady state were not reported.

When Barnes et al was re-analysed using a random effects model accounting for crossover data (figure 1), opioids decreased breathlessness, SMD -0.32 $(95 \%$ CI -0.47 to $-0.18 ; \mathrm{p}<0.001$; $\left.\mathrm{I}^{2}=44.8 \%\right)$ compared with placebo, consistent with the studies by Jennings et al and Ekström et al. Using the SD from a large study, ${ }^{5}$ this effect size corresponds to a reduction of 0.8 points on a $0-10$ numerical rating scale. The finding was

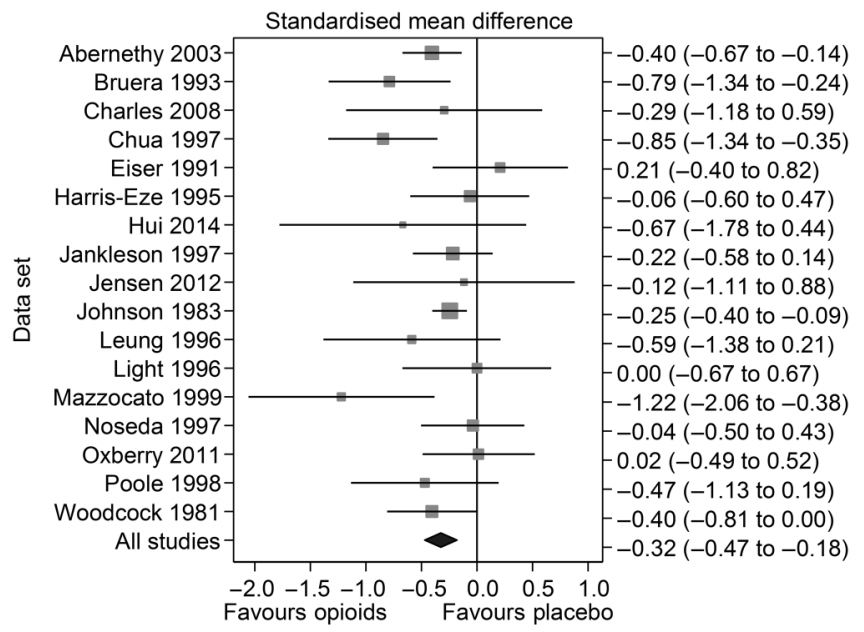

Figure 1 The meta-analysis of Barnes et $\mathrm{al}^{7}$ re-analysed using random effects model and accounting for matched data of crossover trials. In the pooled analysis compared with placebo, systemic opioids reduced breathlessness by a mean $0.32(95 \% \mathrm{Cl} 0.18$ to $0.47 ; \mathrm{p}<0.001)$ SDs. consistent when excluding the three studies for which the SEs were imputed.

\section{Risk of bias and quality of evidence}

Conclusions regarding risk of bias were similar between the studies by Jennings et al and Ekström et al, with unclear or low risk of bias for most items (table 1). In contrast, Barnes et al categorised all studies as having high risk of bias due to low sample size defined as $<50$ participants in each treatment arm. This criterion had no stated rationale and resulted in the quality of evidence for systemic opioids being downgraded from moderate (Ekström et al) to low or very low in the study by Barnes et al (table 1).

\section{DISCUSSION}

The conflicting findings regarding the efficacy of opioids for chronic breathlessness in the recent Cochrane review are likely due to their use of inappropriate methodology. When re-analysed to account for crossover data, opioids were associated with a statistically and clinically significant reduction in breathlessness, ${ }^{9}$ consistent across meta-analyses. ${ }^{346}$

Analysing crossover studies as parallel studies can result in selection bias, with spuriously too high or too low effect estimates, as well as reduced precision. ${ }^{10}$ Recommended methods to account for crossover data are available ${ }^{10}$ and were used by Jennings et al4 and Ekström et $a .^{3} \quad 6$ In addition, study selection should align to predefined eligibility criteria with reasons for exclusion stated to minimise selection bias.

While any judgement of risk of bias is subjective, the bias criterion related to study size introduced by Barnes et al, which resulted in all studies being rates as high risk of bias, is questionable. It is the power of the study which could lead to bias, and not the sample size per se, which is based on the power calculation. Adequate power can be provided by trials with total sample sizes below $50,{ }^{5}$ especially in crossover trials where the participants act as their own control thus increasing power.

We suggest that the analysis by Barnes et $a l$ and the relevant guidelines for analysis and review of the Cochrane Collaboration are updated to accommodate these issues.

\section{CONCLUSION}

Moderate level evidence to date supports that regular, low-dose morphine is the first-line pharmacological treatment for the relief of chronic breathlessness in severe illness. 


\section{Magnus Ekström, ${ }^{1}$ Sabrina Bajwah, ${ }^{2}$ \\ J Martin Bland, ${ }^{3}$ David C Currow, ${ }^{4}$}

Jamilla Hussain, ${ }^{5}$ Miriam J Johnson ${ }^{5}$

${ }^{1}$ Division of Respiratory Medicine \& Allergology, Department of Clinical Sciences, Lund University, Lund, Sweden

${ }^{2}$ Cicely Saunders Institute, King's College London, London, UK

${ }^{3}$ Department of Health Sciences, University of York, York, UK

${ }^{4}$ Discipline, Palliative and Supportive Services, Flinders University, Adelaide, Australia

${ }^{5}$ Hull York Medical School, University of Hull, Hull, UK

Correspondence to Dr Magnus Ekström, Division of Respiratory Medicine \& Allergology, Department of Clinical Sciences, Lund University, Lund SE-22100, Sweden; pmekstrom@gmail.com

Contributors Concept and design: ME, DCC, JMB $M J J, ~ J H$; first draft: ME, SB; statistical analysis: JMB; interpretation, revision and acceptance of the final version to be published: $M E, S B, D C C, J M B, J H, M J J$.

Funding ME was supported by unrestricted grants from The Swedish Society of Medicine, the Swedish Respiratory Society, the Swedish Heart-Lung Foundation, the Scientific Committee of Blekinge County Council and the Wera and Emil Cornell Foundation.

Competing interests DCC has received intellectual property payments and advisory board payments. MJJ has been a clinical consultant for Mayne Pharma. Authors of this paper have longstanding interest in the research of breathlessness and have published several opioid-related trials and meta-analyses (including ME and $D C C^{6}$ ). MJJ was an external clinical academic (not statistical) peer reviewer for the original Barnes et al protocol submitted to Cochrane.

Provenance and peer review Not commissioned; externally peer reviewed.

- Additional material is published online only. To view please visit the journal online (http://dx.doi.org/10. 1136/thoraxjn-2016-209868).

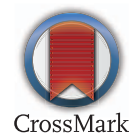

To cite Ekström M, Bajwah S, Bland J M, et al. Thorax 2018;73:88-90.

Received 15 December 2016

Revised 3 March 2017

Accepted 10 March 2017

Published Online First 4 April 2017

Thorax 2018;73:88-90.

doi:10.1136/thoraxinl-2016-209868

\section{REFERENCES}

1 Johnson MJ, Yorke J, Hansen-Flaschen J, et al. Towards an expert consensus to delineate a clinical syndrome of chronic breathlessness. Eur Respir J 2017; In press. doi:10.1183/13993003.02277-2016

2 Ekström MP, Abernethy AP, Currow DC. The management of chronic breathlessness in patients with advanced and terminal illness. BMJ 2015;349: g7617.

3 Jennings AL, Davies AN, Higgins JP, et al. Opioids for the palliation of breathlessness in terminal illness. Cochrane Database Syst Rev 2001; (4):CD002066

4 Jennings AL, Davies AN, Higgins JP, et al. A systematic review of the use of opioids in the management of dyspnoea. Thorax 2002;57:939-44.

5 Abernethy AP, Currow DC, Frith P, et al. Randomised, double blind, placebo controlled crossover trial of sustained release morphine for the management of refractory dyspnoea. $B M$ 2003:327:523-8.

6 Ekström M, Nilsson F, Abernethy AA, et al. Effects of opioids on breathlessness and exercise capacity in chronic obstructive pulmonary disease: a systematic review. Ann Am Thorac Soc 2015;12:1079-92.

7 Barnes H, McDonald J, Smallwood N, et al. Opioids for the palliation of refractory breathlessness in adults with advanced disease and terminal illness. Cochrane Database Syst Rev 2016;3:CD011008.

8 Curtin F, Altman DG, Elbourne D. Meta-analysis combining parallel and cross-over clinical trials. I: continuous outcomes. Stat Med 2002:21:2131-44.

9 Johnson MJ, Bland JM, Oxberry SG, et al. Clinically important differences in the intensity of chronic refractory breathlessness. J Pain Symptom Manage 2013:46:957-63.

10 Curtin F, Elbourne D, Altman DG. Meta-analysis combining parallel and cross-over clinical trials. III: The issue of carry-over. Stat Med 2002;21:2161-73. 